\title{
Corrigendum: 3D motion analysis of cervical spine joints of dental hygiene students and dental hygienists during scaling operation
}

\author{
Ka-Yeon Lee ${ }^{1}$, Ji-Hee Kim²
}

${ }^{1}$ Department of Dental Hygiene, Ulsan College, Ulsan, ${ }^{2}$ Department of Dental Hygiene, Kyungnam College of Information \& Technology, Busan, Korea

Journal of Korean Academy of Oral Health 2021 September 45(3):151-155

https://doi.org/10.11149/jkaoh.2021.45.3.151

저널의 45-3호에 사사문구가 저자의 실수로 인해 미기재되어 기재 요청드립니다.

기재 내용은 다음과 같습니다.

\section{Acknowledgements}

이 논문은 2020년 울산과학대학교 교내학술연구비 지원에 의해 수행됨. 